\title{
COR E PERCEPÇÃO AMBIENTAL: UM ESTUDO DE CASO EM UMA BIBLIOTECA UNIVERSITÁRIA
}

\author{
SOARES, Cristiana (1); \\ BARROS, Bruno (2) \\ (1) Universidade Federal de Pernambuco, Bacharel \\ e-mail: brunoxsbarros@gmail.com \\ (2) Universidade Federal de Pernambuco, Mestre \\ e-mail: barros bruno@hotmail.com
}

\begin{abstract}
RESUMO
O uso equivocado de uma paleta de cores em um ambiente pode prejudicar diretamente a qualidade do espaço. Como exemplo, temos os ambientes de estudo, os quais requerem uma composição cromática adequada, que influencie de forma positiva os estudos dos alunos. Dentro deste contexto, esta pesquisa buscou realizar uma análise da percepção cromática de uma biblioteca universitária. A composição cromática do espaço foi analisada sob dois aspectos, a saber: 1. sob a ótica da literatura; e 2. sob a ótica dos usuários (estudantes da instituição). A pesquisa identificou indutivamente uma composição cromática monótona e desestimulante sob os dois aspectos estudados.
\end{abstract}

Palavras chave: Percepção ambiental; cor; biblioteca.

\begin{abstract}
Inappropriate use of a color palette in environments can degrade the quality of the space. As an example, there are the study environments, which require an adequate chromatic composition, that influences in a positive way the understanding of the subjects studied in the space. Within this context, this research sought to perform an analysis of the chromatic perception of a university library. The chromatic composition of space was analyzed under two aspects, namely: 1. from the perspective of the literature; and 2. from the viewpoint of the users (students of the institution). The research identified inductively a monotonous and discouraging chromatic composition under the two studied aspects.
\end{abstract}

Keywords: environmental perception; color; library.

\section{INTRODUÇÃO}

As cores, quando são utilizadas de forma equivocada, podem ser prejudiciais no desempenho do trabalho humano. Elas, por sua vez, podem trazer consigo vários significados e simbolismos, dependendo do ambiente em que estão inseridas e do público com o qual irá entrar em contato. As cores podem ser compreendidas de diversas maneiras, 


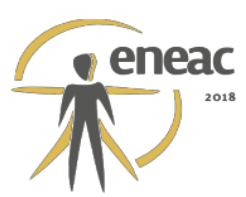

por exemplo, a percepção de um indivíduo com a cor vai além do que ele está vendo, ela pode ser associada diretamente com experiências e sensações anteriores interligadas àquela cor, que automaticamente irá Ihe trazer lembranças agradáveis ou desagradáveis.

Cabe ainda destacar as influências orgânicas que as cores trazem ao ser humano. Após a captação e identificação da cor, o cérebro recebe informações de outros órgãos sensoriais que estimulam diversas sensações no indivíduo. Deste modo, o uso das cores pode interferir e influenciar no sistema orgânico do ser humano. Um exemplo bastante corriqueiro são as cores amarelo e vermelho, bastante aplicadas em estabelecimentos alimentícios, são cores quentes e vibrantes que estimulam o apetite, porém, quando usadas em excesso, podem deixar o ambiente aparentemente agressivo e irritante.

Um ambiente pode trazer sensações que são capazes de incentivar e desestimular as atividades exercidas pelo usuário através das características que o espaço possui. Desta forma, podemos dizer que a adequação cromática dos ambientes de estudo é de extrema importância no desempenho cognitivo dos alunos que utilizam o local, uma vez que, cada cor possui significados e influências diferentes que podem atuar de forma positiva ou negativa. Identificamos em lida (2005, p.360) uma confirmação a essas circunstâncias quando o autor fala que: "monotonia e motivação são processos que sobrepõem à fadiga, podendo agravá-la ou aliviá-la. Eles são causados por estímulos ambientais, que podem ser monótonos ou motivadores".

Diante deste conteúdo, a referente pesquisa repousou o foco no processo de sinestesia cromática proporcionado por um dos ambientes que compõe uma biblioteca universitária. Partiu-se da hipótese de que o espaço em estudo não foi projetado sob bases humanas de adequação cromática. Desta forma, o esquema de cores aplicado na área de estudo poderia estar interferindo negativamente no desempenho dos estudos dos alunos que frequentam o ambiente. Para tanto, concentramo-nos em identificar como seria a percepção ambiental dos alunos em relação à composição cromática do espaço.

\section{FUNDAMENTAÇÃO TEÓRICA}

A percepção ambiental vem sendo considerada um aspecto fundamental na saúde e bemestar do ser humano, visto que ambientes mal projetados com má qualidade física e espacial conduzem a insatisfação dos usuários, causando instabilidades emocionais e comportamentos destrutivos. As ações do homem sobre as influências ambientais podem gerar diversas consequências podendo interferir na qualidade de vida dos usuários (RHEINGANTZ, ALCANTARA e RIO, 2005). De acordo com Okamoto (2002), a percepção acontece através das captações dos estímulos externos através da leitura dos cinco sentidos humanos, principalmente pela visão. Também acontecem através dos processos cognitivos, que associam a cultura, valores, experiências, entre outros (DEL RIO, 1999).

O comportamento do indivíduo no espaço é gerado pelas suas particularidades e pela percepção do ambiente, que são comportamentos influenciados pelos estímulos ambientais (RANGEL E MONT'ALVÃO, 2015, p.04). De acordo Sobral, Paiva, Porto e Villarouco (2015), a relação humano-espaço interfere no estado comportamental e no estado de humor, desta forma, o comportamento humano é consequência da sua relação com as características espaciais, evidenciando assim a importância da compreensão do sistema pessoa-ambiente, para que se identifique a forma que o usuário interpreta o local e a forma que ele se relaciona com o espaço.

Dentro deste contexto, Vasconcelos, Soares \& Villarouco (2009, p.7) mencionam como fundamento indispensável para a percepção os Aspectos psicológicos - sensações dos usuários (através da percepção do usuário sob o ambiente), comunicação humana e estética e limite espacial. Desta forma, no desenvolvimento de ambientes, é de grande importância levar em consideração os aspectos psicológicos da percepção do ser humano, 


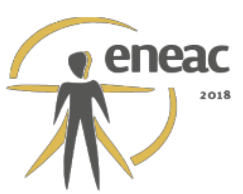

para que se tenha um ambiente adequado e eficaz. Segundo Fonseca (2004), um dos maiores fatores de "estresse ambiental" nos locais de trabalho é a falta de estímulos ambientais. Desta forma é necessária a utilização de elementos sensoriais que causem incitações e que provoquem respostas comportamentais positivas. Costi (2002) consolida essa afirmação quando alega que a cor é um estímulo psíquico muito importante, podendo confundir o estado emocional, trazendo sensações tranquilizantes ou estimulantes, dependendo da forma que é aplicada. Em ambientes de estudo, os usuários devem se sentir motivados e estimulados e a utilização da cor com moderação é uma solução para que não haja interferência na concentração (CARNEIRO, 2012).

O ambiente de uma biblioteca, segundo Prado (2003), deve ser satisfatório aos usuários, bem projetado e organizado, com características ambientais que inspirem o ar positivo, como as cores e os mobiliários, já que se trata de um ambiente onde os usuários costumam passar algumas horas. Desta forma, é preciso ter em mente que a paleta cromática de um ambiente pode trazer várias características quando relacionada a temperatura ambiental, interferindo nas sensações que o ambiente poderá causar ao usuário (GURGEL, 2012). As utilizações das cores nos ambientes podem servir como estímulo, podendo influenciar no comportamento, no humor, na satisfação e na motivação do usuário. As influências que essas cores podem trazer ao usuário podem ser úteis para projetos de ambientes direcionados ao trabalho (STONE, 2001).

Mateus et al. (2015), afirmam que ambientes de estudo devem possuir paredes e tetos pintados em tons claros, com o objetivo de propagar uma melhor iluminação no ambiente. Ressaltam também que as carteiras devem ser de cores claras e foscas, para que não provoque um cansaço mental aos usuários. Thompson (2003), retrata que a mudança de cores de uma instituição educacional é uma maneira rápida e de menor custo para melhorar o ambiente. O autor recomenda pintar as salas com uma cor em destaque, e as cores neutras e clássicas aplicadas nas outras paredes, de forma que as mesmas se harmonizem. A compra de tintas em grande quantidade é uma estratégia para reduzir os custos, porém a escolha das cores poderá trazer benefícios valiosos, comparado a um mínimo custo adicional.

Deve-se evitar a utilização de uma única cor em ambientes educacionais, o ambiente deve ser enriquecido pela variedade de cores levando sempre em consideração a diversificação dos usuários (RAMPUANO GUIDALLI, 2012). Concordando com este pensamento, Costi (2002), afirma que o cérebro humano necessita de uma variedade de estímulos, que uma só cor em um ambiente traz uma sensação monótona, apresentando apenas valores negativos, uma vez que um ambiente monótono e estático induz a ansiedade, a tensão, ao medo e ao sofrimento.

Ao logo dos anos, as cores e seus sentidos psicológicos têm sido foco de diversas pesquisas, as quais têm atingido resultados bastante similares entre si. Uma síntese de alguns desses significados psicológicos podem ser acompanhados no quadro que se segue.

Tabela 1: Tons e significados psicológicos

\begin{tabular}{|l|}
\hline a) Tons de Amarelo \\
\hline Para lida (2005) é uma cor luminosa e digna, evoca dominação, riqueza material e espiritual. \\
Representa calor, energia, claridade. Associada a cor do sol, ouro e do fruto maduro. Às \\
vezes é associada ao despeito, traição, solidão, desespero, por ser intensa e aguda. Gurgel \\
(2012) faz referência ao sol e à infância. É uma cor otimista, iluminam, estimulam o intelecto, \\
a criatividade e ajudam na digestão. O excesso pode estimular demais, causando estresse. \\
ldeal para copas, salas de estudos, de leitura e ambientes que são mais utilizados no \\
período da manhã. Tende a estimular o cérebro e gerar alegria. Heller (2013) afirma ser a \\
cor predileta de $6 \%$ dos homens e das mulheres. Apreciada mais \\
por pessoas mais velhas. Possuem simbolismo do sol, da luz e do ouro. É uma cor \\
\hline
\end{tabular}




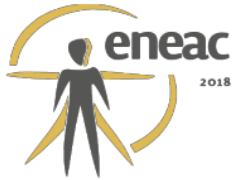

considerada bastante instável. É a cor do otimismo, mas também da irritação, da hipocrisia e da inveja. Ela é a cor da iluminação, do entendimento, mas também é a cor dos desprezados e dos traidores. Considerada extremamente ambígua. Lacy (2011) destaca que é bastante associado ao conceito de luz, considerada uma cor quente e possui um elevado índice de reflexão. É uma cor vibrante e extravagante. Quando utilizado de forma correta pode trazer benefícios, como a utilização dele em ambientes com atividades monótonas e que exija concentração, deixando o ambiente mais alegre, dinâmico e produtivo.

b) Tons de Laranja

Para lida (2005), o laranja é uma cor quente, viva, acolhedora, saliente. Evoca fogo, o sol, a luz e o calor. Possui um poder de dispersão. É considerada uma cor psicologicamente ativa e capaz de facilitar a digestão. Gurgel (2012) afirma que estes tons são relacionados à capacidade de associação do ser humano. Estimulam o otimismo, elevam o espírito. Cor da criatividade, da alegria e do humor, podendo ser utilizada em combate a depressão. É mais quente que o amarelo, ajudam na criação de ambientes mais aconchegantes. Também é estimulante e aguça o apetite. Heller (2013) ressalta que é a cor predileta em 3\% das mulheres e $2 \%$ dos homens. O laranja muitas vezes denota o verdadeiro caráter de um sentimento, ele combina as contradições do vermelho e do amarelo fortalecendo seus pontos em comum. Lacy (2011) a classifica como uma cor quente, estimulante, alegre e criativa. Associada a ação e ao entusiasmo.

\section{c) Tons de Vermelho}

lida (2005) destaca que é uma cor considerada uma cor quente, saliente, agressiva, estimulante e dinâmica. Associada ao fogo e ao sangue. Para Gurgel (2012), estes tons lembram o fogo, calor, sangue, romance e agressividade. Podem acelerar a pulsação, estimulam o apetite e a "ação". Ajudam na racionalidade das pessoas, tendendo a deixa-las mais objetivas e diretas nas conversas. Em excesso em locais pequenos podem causar a sensação de claustrofobia. É uma cor adaptada a pessoas mais extrovertidas, pode estimular a conversas e discussões. O tom magenta pode estimular e induzir mudanças, pois traz em si a energia de transformação. Heller (2013) afirma ser a cor predileta em 12\% das mulheres e dos homens. Uma cor que agrada mais os mais velhos. Associados ao fogo, sangue, amor, paixão, ódio, luxo, pecado e ao perigo. Lacy (2011) caracteriza como uma cor quente, forte, estimulante e bastante impactante. Deve ser utilizada com cautela.

d) Tons de Violeta

Para Gurgel (2012) são cores mágicas, associadas aos sonhos e fantasias. São sofisticadas, representam sensibilidade, estimulam a intuição e a espiritualidade. Podem reduzir o estresse. Boa sugestão para áreas de estudo, de música e relaxamento. Seus tons mais fortes podem deprimir, indicado para utilizar com tons neutros ou fracos. Em tons mais azulados ajudam a relaxar, em tons mais vermelhos tendem a ser mais quentes e estimulantes. Heller (2013) afirma ser a cor predileta em $12 \%$ das mulheres e $9 \%$ dos homens. Associados a sensualidade, espiritualidade, magia e homossexualidade. Lacy (2011) destaca que esta é uma cor considerada uma cor equilibrada. Deve-se evitar a

atualização dela em grande quantidade, em excesso pode deixar o ambiente desestimulante.

e) Tons de Azul

lida (2005) caracteriza como cores frias, calmas, repousantes, soníferas. Sugerem indiferença, imprudência e passividade. Evoca o ar, o mar e o espaço. Traz sensação de frescor. Exerce apelo intelectual, simbolizando inteligência e raciocínio. Gurgel (2012) afirma que lembram o céu, o mar, a água e o espaço. São cores relaxantes, frescas, tranquilizantes, pacíficas e ajudam a acalmar. Tendem a desacelerar os batimentos cardíacos e diminuir a pressão sanguínea. Em tons claros ajudam a diminuir o estresse e a ansiedade. Em tons escuros e fortes podem estimular a introspecção e consequentemente, depressão. Tons claros são mais frescos, já que as mais acinzentadas podem parecer sem vida, apagadas e monótonas. Tons fortes e vibrantes são poderosos e transmitem paz. Azul 


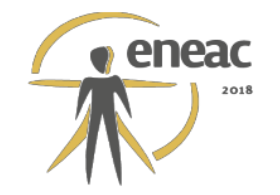

turquesa, ajudam a aliviar o estresse e a tensão, podendo ser utilizado em salas de estudo juntamente com laranja ou amarelos. São estimulantes e exóticos. Heller (2013) destaca que a cor azul é a mais preferida entre as cores, predileta de $46 \%$ dos homens e $44 \%$ das mulheres. Associadas ao frio e frescor, possuem a sensação de calmante. Associadas principalmente a todos os bons sentimentos, podem trazer harmonia, simpatia, confiança, estimular a amizade, fantasia, divino, mar e ao céu. Lacy (2011) explica que estes tons se traduzem em uma cor fria e relaxante, quando em composição com cores quentes traz equilíbrio. Bastante associada a cultura ocidental, em tons mais escuros traz a sensação de frieza e formalidade.

f) Tons de Verde

Para lida (2005) o verde é uma cor passiva, sugere imobilidade, alivia tensões e equilibra o sistema nervoso. Não se deixa acompanhar de alegria, tristeza e paixão. Ajuda a acalmar e a diminuir a tensão nervosa e a pressão sanguínea. Por isso é bastante utilizada em hospitais. É simbolicamente associada a esperança, felicidade e liberação do movimento para frente (sinal verde). Gurgel (2012) defende que são cores frescas, equilibradas, harmoniosas e relaxantes. Nos transportam à floresta, ao jardim, ao mato, ao campo e ao espaço aberto. Ajudam a criar uma atmosfera calma e equilibrada. Em excesso podem estimular a empatia e indiferença nas pessoas. Heller (2013) destaca que esta não é a cor preferida, predileta de $16 \%$ dos homens e $15 \%$ das mulheres. Apreciado mais com a idade. Associados a natureza, ideologia, consciência ambiental, saúde, fertilidade, frescor e esperança. Lacy (2011) afirma que esta cor é considerada uma cor calma, tranquilizante e equilibrada. Em seus tons mais claros trazem sensação de bem-estar, já em seus tons mais escuros tenciona a depressão.

g) Preto

lida (2005) acredita que esta é uma cor considerada uma cor deprimente, lembra o frio e a sombra, o céu noturno, a tristeza, ao mal, ao diabo, a morte, etc. É considerado como símbolo de luto. Heller (2013) afirma que o preto é considerado a ausência de todas as cores mais preferido entre os jovens. Associado ao luto, ao fim, a dor, negação, sujeira, mal, autoridade e elegância.

\section{h) Branco}

lida (2005) relata que o branco é uma cor associada à pureza, inocência, simboliza a paz ao nascimento e a morte. Heller (2013) destaca que o branco lembra a luz, a ressureição, ao início, ao bem, a inocência, a limpeza, pureza e a leveza.

Fonte: Adaptado de lida (2005), Gurgel (2012), Heller (2013) e Lacy (2011).

Desta forma, podemos entender que os ambientes exercem influências no desempenho das atividades dos usuários que frequentam um determinado espaço, podendo interferir no comportamento, na produtividade e na saúde psicofísica, de forma positiva ou negativa. Desta maneira o conhecimento por características ambientais que satisfaçam as necessidades humanas é de grande importância, sempre levando em consideração que as configurações ambientais podem variar e, para que isso ocorra da melhor forma, o projeto deve entender as necessidades de uso, o tipo de usuário e as atividades que serão exercidas no ambiente. entre as características que compõem o ambiente, destaca-se a cor através das suas características e influências comportamentais (SILVA E BORMIO, 2016).

\section{METODOLOGIA}

Este estudo buscou identificar como seria a percepção ambiental dos alunos em relação à composição cromática de um espaço de estudo de uma biblioteca universitária. Para a condução da referente pesquisa, selecionou-se como método de abordagem o Método Indutivo, que se caracteriza pela análise de experiências de um grupo particular para chegar 


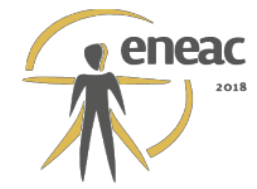

a conclusões generalizadas, o pesquisador pode alcançar informações e resultados através da observação de casos específicos que envolvem o objeto. No estudo em questão é realizada uma pesquisa na biblioteca selecionada, identificando seus principais problemas para que se proponha um espaço adequado, permitindo a generalização destes resultados para diversos outros ambientes de ensino nas mais diversas localidades.

A captação da percepção dos usuários foi obtida por meio de um pequeno questionário online, pelo Google Formulários, onde os alunos selecionaram as sensações transmitidas através das cores do ambiente, notificando se o ambiente está cromaticamente adequado para as atividades exercidas no espaço. A divulgação desse questionário foi realizada através dos grupos de alunos da universidade em redes sociais. A enquete foi direcionada apenas aos alunos do campus que frequentam o local de estudo, por se tratarem dos usuários principais com espaço. O questionário ficou disponível on line para receber respostas durante um período de 9 dias.

O questionário proposto se enquadrou na forma estruturada/padronizada, composto por apenas uma pergunta, a qual solicitava que o aluno respondente selecionasse as sensações que as cores do ambiente transmitiam. Como auxílio, disponibilizamos no questionário uma fotografia panorâmica do espaço. Foram dispostas aleatoriamente 18 sensações, sendo nove extraídas das possíveis sensações transmitidas pelas cores do ambiente, baseados no referencial teórico (frio, calma, monotonia, seriedade, tédio, tristeza, angústia, relaxamento e cansaço), e nove sensações opostas a elas (empolgação, animação, calor, irritação, alegria, agitação, prazer, descontração e entusiasmo), para que os alunos pudessem expor sua percepção.

Figura 1 - Espaço selecionado para estudo de caso.

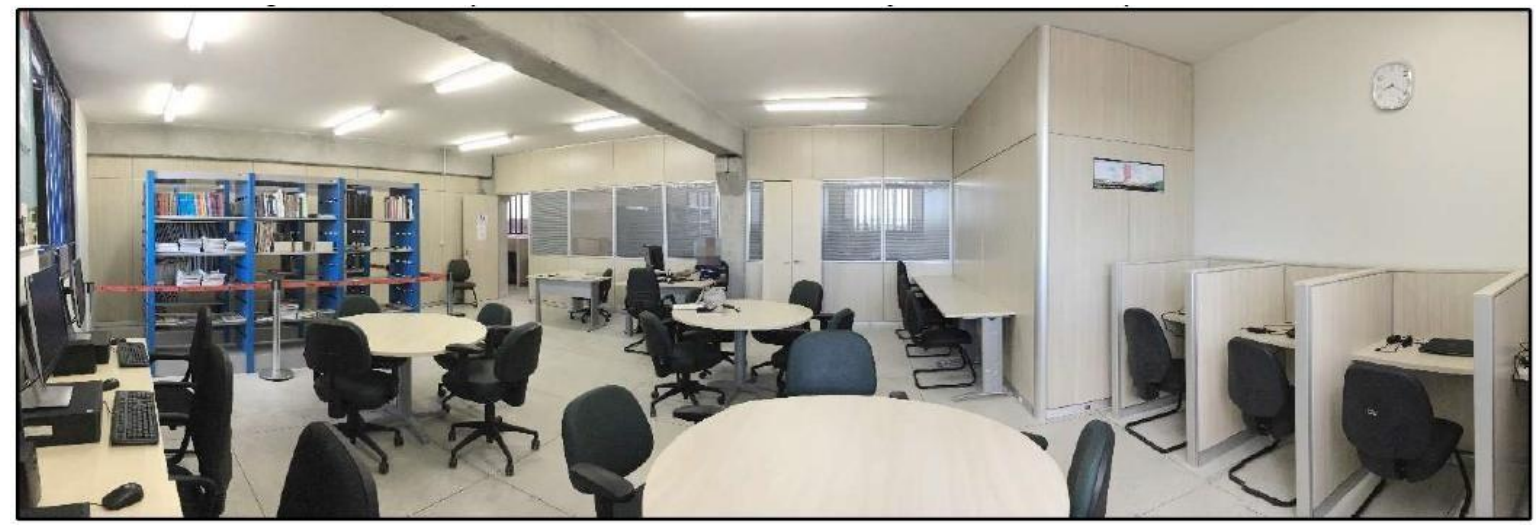

Fonte: Capturado pelos autores para a pesquisa.

Como voluntários da pesquisa, não puderam ser considerados os funcionários da instituição, pelo fato do ambiente não ser direcionado à utilização dos mesmos para estudos, nem pessoas com deficiência visual grave, a qual os impedissem ou dificultasse consideravelmente a visão, tais como glaucoma, catarata, daltonismo e até cegueira. Também não foram considerados indivíduos com limitações cognitivas, as quais os impedissem de expressar sua percepção ou estimulassem uma percepção diferenciada. Foram desconsideradas ainda pessoas que não estivessem cursando alguma graduação na instituição de ensino, assim como professores, sendo este último porque possuem sala própria e não costumam utilizar o referido espaço de estudo.

Como pode-se notar, o ambiente citado possui uma prevalência maior de cores neutras. Os planos horizontais (teto e piso) são branco e cinza claro respectivamente, e os planos verticais (paredes) são em dois tons, sendo o de alvenaria em um tom pastel neutro (bege) 


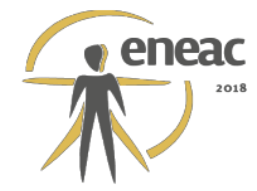

e divisórias de madeira na cor marfim encaixadas por esquadrias na cor prata, as cabines de estudos individuais seguem o mesmo padrão das divisórias. As mesas seguem o mesmo material e tom das divisórias de madeira em seus tampos, já os pés variam em tons de cinza. Existem três modelos de cadeiras, as que ficam nas mesas redondas que são compostas pelo verde escuro (acento e encosto estofado) e o preto (pés, braços e parte externa do acento e do encosto), os outros dois modelos utilizam apenas o preto. Há duas estantes na cor azul e uma faixa de isolamento na cor vermelha, ambos se destacam no ambiente por serem os únicos objetos com cores vibrantes.

Desta maneira, foram identificados seis tons, os que possuem maior predominância nas superfícies do ambiente, para representar a paleta de cores do espaço (figura 2). De forma que esses tons podem sofrer variações de acordo com a superfície, como o cinza, que é encontrado no piso e nas esquadrias.

Figura 2 - Paleta de cores do ambiente de estudo analisado.

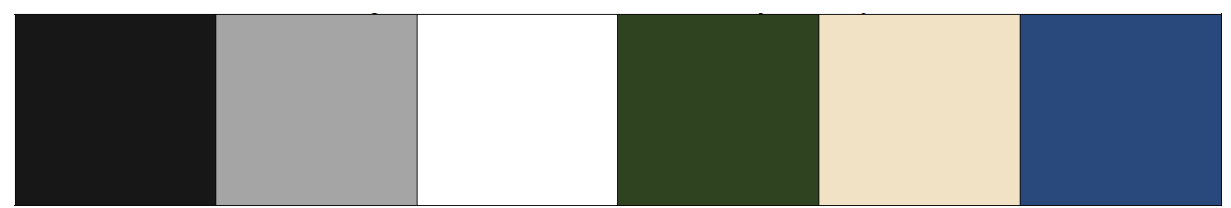

Fonte: Elaborado pelos autores para a pesquisa.

De acordo com a paleta de cores que retrata o ambiente em estudo (figura 2), é possível observar que a mesma é composta principalmente por cores neutras e frias (preto, cinza, branco, verde, bege e azul).

É importante destacar que, nesta pesquisa, além destes tons terem sido postos para avaliação de forma aplicada ao ambiente, por meio da entrevista com os alunos, também foram submetidos a uma verificação sob a ótica da literatura, com intuito de verificar os diagnósticos teóricos acerca das sensações sinestésicas impostas por tais cores.

\section{RESULTADOS}

Segundo a bibliografia estudada, ambientes de estudo necessitam de estímulos visuais (cores) que atuem de forma benéfica aos usuários e consequentemente, nas atividades que serão exercidas no espaço. Desta forma, a composição cromática dos ambientes de estudo deve ser equilibrada, com a utilização de cores frias, quentes e neutras, em suas variações de tons.

A análise da composição cromática do ambiente de estudo da biblioteca, sob a ótica da teoria, revela a ausência de cores quentes e estimulantes. Desta maneira, a paleta de cores do espaço se traduz em um ambiente frio, calmo e monótono, podendo trazer outras inúmeras sensações derivadas dessas três principais, as quais venham a prejudicar o desempenho dos estudos dos alunos.

Sob a ótica da percepção ambiental dos alunos, verificou-se que participaram voluntariamente da pesquisa 103 estudantes, respondendo ao questionário eletrônico, sendo estes de diversos cursos, turnos, áreas, gêneros e idades. O gráfico 1 apresenta os resultados da pesquisa em ordem de frequência, expondo as sensações transmitidas pelas cores do ambiente através das percepções dos alunos. Lembramos que foram dispostas 18 (dezoito) sensações, e cada aluno entrevistado poderia selecionar até 9 (nove) sensações. 


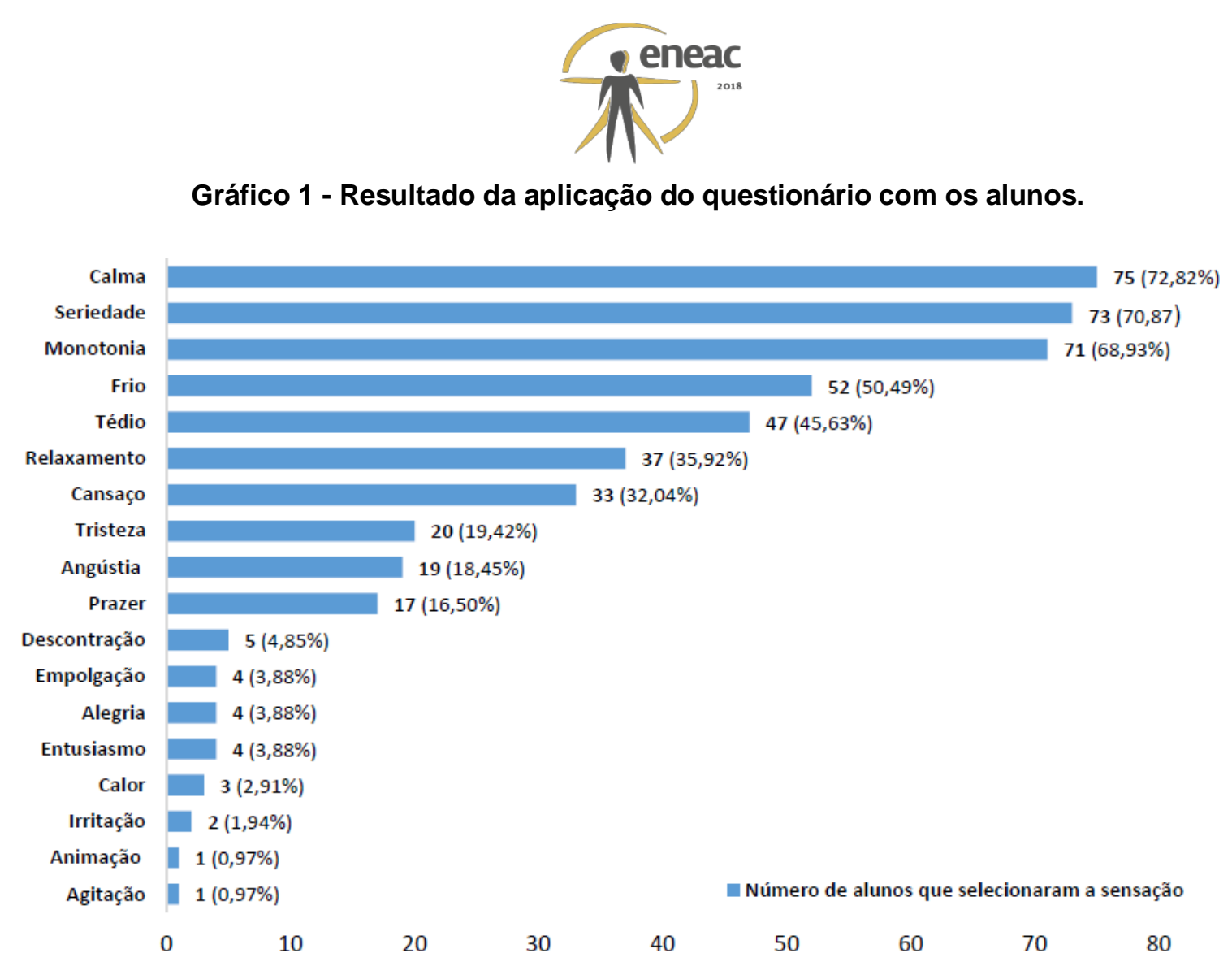

Fonte: Elaborado pelos autores para a pesquisa.

Baseado nos resultados do gráfico 1, foram extraídas as nove sensações mais votadas pelos alunos, de acordo com as sensações que as cores do ambiente transmitiam a cada um deles, e o resultado foi representado quadro que se segue.

Tabela 2 - Sensações mais votadas pelos alunos.

\begin{tabular}{|c|c|c|c|}
$\begin{array}{c}\text { 9 sensações } \\
\text { mais votadas }\end{array}$ & $\begin{array}{c}\text { Porcentagem de } \\
\text { alunos que votaram }\end{array}$ & \multicolumn{2}{|c|}{$\begin{array}{c}\text { Cores que provocam essas sensações no ambiente } \\
\text { atualmente }\end{array}$} \\
\hline Calma & $72,82 \%$ & & \\
\hline Seriedade & $70,87 \%$ & & \\
\hline Monotonia & $68,93 \%$ & & \\
\hline Frio & $50,49 \%$ & & \\
\hline Tédio & $45,63 \%$ & \\
\hline Relaxamento & $35,92 \%$ & & \\
\hline Cansaço & $32,04 \%$ & & \\
\hline Tristeza & $19,42 \%$ & & \\
\hline Angústia & $18,45 \%$ & \\
\hline
\end{tabular}

Fonte: Elaborado pelos autores baseado em lida (2005), Gurgel (2012), Heller (2013) e Lacy (2011). 


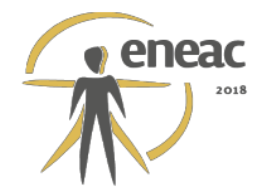

O estudo nos ofereceu subsídios para acreditar que, devido à aplicação incorreta das cores no ambiente, o mesmo possui um desequilíbrio harmônico e visual quanto ao objetivo do espaço. Um ambiente de estudo deveria estimular a concentração, a segurança e o aprendizado, entretanto, o excesso das cores bege, preta e cinza proporcionam desconforto aos alunos, provocando sensações indesejáveis como monotonia, tédio, tristeza e angústia. Sensações estas que se confirmaram bastante semelhantes tanto na análise teórica quanto na identificação da percepção dos estudantes.

Com base nos resultados obtidos através da análise teórica e de percepção dos estudantes, a condução deste estudo nos permitiu elaborar um projeto conceitual cromaticamente adequado aos objetivos do ambiente, o qual servisse de exemplo de referência visual para uma reestruturação das cores do ambiente para que este pudesse proporcionar um melhor desempenho nos estudos dos alunos que utilizam o espaço. Concentramo-nos no fato de que ambientes de estudo necessitam ser cromaticamente equilibrados com cores quentes (estimulantes, alegres e vibrantes), frias (tranquilizantes e relaxantes) e neutras (iluminando, equilibrando e contrastando). Pensando desta forma e com o objetivo de deixar o ambiente mais estimulante para as atividades que são desenvolvidas nele, foi proposta uma nova paleta de cores entusiasmante e equilibrada, de forma que impulsione um fortalecimento na qualidade e no rendimento dos estudos dos alunos que frequentam o espaço (figura 3).

Figura 3 - Paleta de cores selecionada para o projeto proposto.

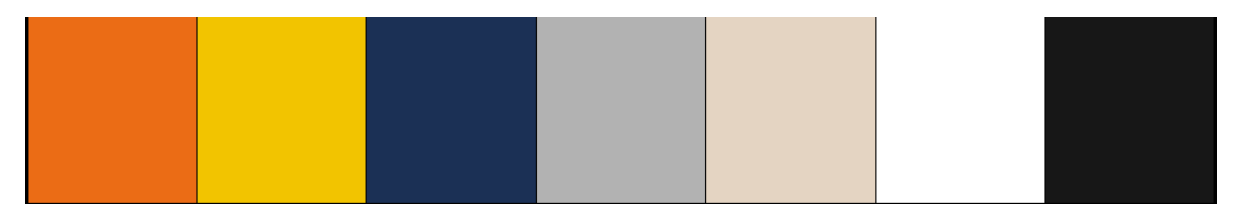

Fonte: Elaborado pelos autores baseado em lida (2005), Gurgel (2012), Heller (2013) e Lacy (2011).

Com objetivo de propor um projeto cromático baseado na funcionalidade e no bem-estar dos usuários selecionou-se um grupo de cores considerando, como alerta, as sensações mais votadas pelos estudantes, a maioria delas consideradas desagradáveis para a função do ambiente e para os alunos.

A composição cromática dessa nova paleta teve o objetivo de extinguir as sensações negativas das atuais cores do espaço, percebidas pelos estudantes. As sensações de relaxamento e calma, não foram consideradas negativas, porque ambientes de estudo devem ser calmos e relaxantes, uma vez que as pessoas necessitam sentirem-se calmas e relaxadas para se concentrarem, porém o ambiente não só deve ser composto por estímulos que tragam apenas essas sensações, ou sensações semelhantes.

A paleta selecionada (figura 3) representa as cores que possuem uma maior predominância nas superfícies dos objetos que compõem o projeto proposto (figura 4), porém, as cores possuem variações de tons, deixando o ambiente mais harmônico e agradável. Ao ser direcionado ao estudo e a pesquisa, o ambiente dispõe de espaços de estudos em grupos e individual. Dessa maneira, a aplicação de cada uma das cores foi pensada e direcionada para cada cenário, levando sempre em consideração a composição cromática do ambiente como um todo. 


\section{(x) $^{\text {enac }}$}

Figura 4 - Projeto cromático conceitual proposto.

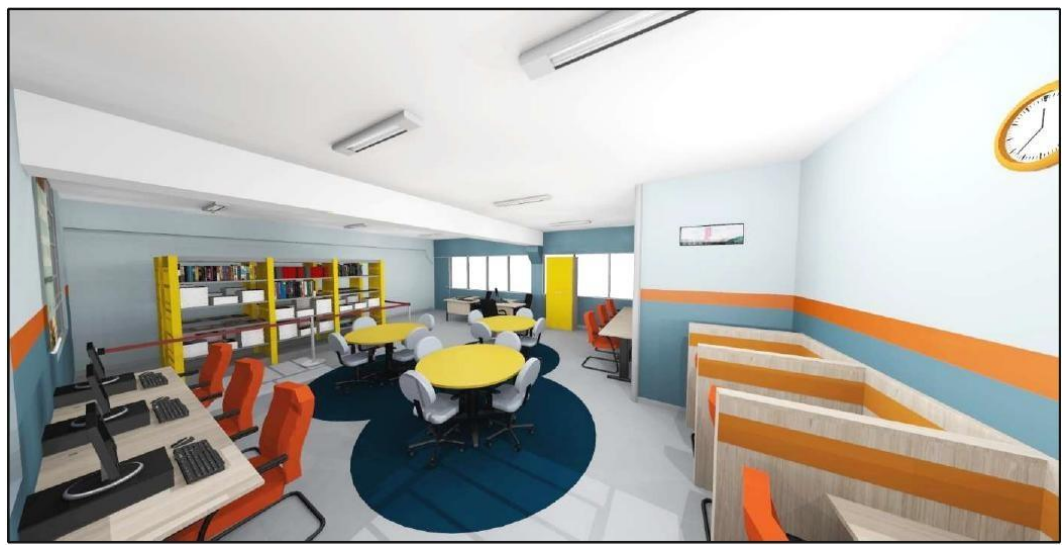

Fonte: Elaborado pelos autores para a pesquisa.

A cor selecionada para possuir uma maior predominância das superfícies foi o azul, sendo aplicado em todas as paredes em dois tons diferentes (azul celeste e azul turquesa), nos "tapetes/adesivos" das mesas redondas (azul marinho) e nas cadeiras centrais o azul celeste, compondo com as paredes. O azul foi aplicado dessa forma por possuir propriedades sinestésicas que favorecem ao estudo. É a cor que evidencia os bons sentimentos, é agradável a maioria das pessoas, e tem o poder de acalmar, relaxar e tranquilizar. Incentiva o intelecto e o raciocínio, estimulando a mente e a intuição, sendo ideal para ambientes de atividades monótonas que exijam concentração. Cores frias nas paredes deixam o ambiente mais agradável e menos cansativo e, por isso, tendem a aumentar o tempo de permanência dos usuários no espaço.

Desta maneira, o azul das paredes irá atuar de forma favorável nas mesas de estudos individuais, nas mesas de pesquisas (mesas com computadores), e nas cabines (baias) de estudos. Entre os azuis das paredes foi aplicado um roda meio laranja, dando um contraste, como forma de prevenção a fadiga. O laranja foi utilizado nos cenários de estudos individuais por possuir uma energia prazerosa, cor bastante utilizada em combate a depressão, trazendo a sensação de vigor, força e ação, tornando os alunos mais dispostos aos estudos. Nesse cenário foi intensificado o revestimento melamínico para um tom de madeirado mais escuro, trazendo a sensação de aconchego e acolhimento, deixando o aluno mais seguro e confortável para o desenvolver das atividades. Nas cadeiras de estudos individuais foi aplicado um laranja mais vivo, compondo com o roda meio e deixando o ambiente mais alegre e dinâmico.

Nas mesas centrais foi utilizado o azul mais escuro em composição com amarelo (cores complementares). O amarelo foi utilizado para as mesas de estudo em grupo por ser uma cor alegre, que ajuda no processo de aprendizagem e ativa a mente para novas ideias (troca de conhecimentos entre os alunos). Foi aplicado seu tom na base (tampo), direcionando a atenção (cor vibrante) dos alunos para a mesa, uma vez que as mesas centrais tendem a dispersar mais a atenção, por ficarem entre as áreas de circulação. $O$ azul marinho e o amarelo juntos produz um equilíbrio visual, provocando a sensação de afetuosidade, desta maneira, foi aplicado um contorno nesse tom nas mesas amarelas, de forma que quando os estudantes direcionarem o ângulo de visualização para as mesas também irá visualizar o azul marinho. O amarelo tende a deixar as pessoas mais espontâneas, possibilitando uma melhor interação entre elas.

O branco foi utilizado no teto com objetivo de propagar uma melhor iluminação para todo o ambiente, a viga também foi pintada da mesma cor do teto com o intuito de camuflar a mesma. O preto foi utilizado nas cadeiras dos funcionários, trazendo a sensação de 


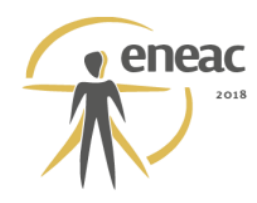

imponência, e em alguns detalhes das cadeiras e das mesas dos estudantes, dando um toque de requinte e seriedade.

O cinza por também ser uma cor neutra, foi aplicado no piso, e em alguns detalhes (perfil das janelas, rodapés e prateleiras da estante), trazendo um toque de seriedade, elegância e naturalidade. $\mathrm{Na}$ estante foi aplicado em composição com o amarelo, trazendo sensação de equilíbrio com ambiente. Com o mesmo intuito de integração e harmonia, foi aplicado o amadeirado e o amarelo no armário. Ambos (estantes e armário) possuem a parede por trás azul, integrando com outros detalhes do ambiente e trazendo um toque de alegria.

É importante destacar que as superfícies dos objetos que compõem o ambiente são foscas (sem reflexos), com objetivo de não provocar cansaço mental nos usuários. Em tempo, alertamos que, de acordo a norma da ABNT - NBR 7195/1995, a utilização da cor vermelha também é utilizada para sinais de parada obrigatória e de proibição, desta forma, a faixa de isolamento do acervo foi mantida em sua cor original (vermelha), por questões de segurança e isolamento da área para acesso restrito de funcionários.

\section{CONCLUSÕES}

O presente estudo alcançou os objetivos esperados através da identificação dos problemas ocasionados pelas cores, apontados na identificação da percepção ambiental por parte dos alunos. Ofereceu-se ainda uma sugestão cromática como forma de combater as sensações que vinham prejudicando o desempenho dos estudos dos alunos que utilizam o espaço, com o propósito de aumentar o rendimento dos estudos dos alunos, além de proporcionar um ambiente agradável e funcional. Ambientes de estudos exigem concentração e motivação, as cores desses ambientes devem provocar esses estímulos de forma benéfica.

Durante o desenvolver da pesquisa e da fundamentação teórica, foi possível notar uma carência de estudos realizados que abordassem as sensações sinestésicas das cores em ambientes de estudo, principalmente em universidades.

Instituições de ensino, principalmente públicas, tendem a optar por um "padrão" em ambientes que possuem finalidades distintas, como um refeitório e um ambiente direcionado aos estudos, os mesmos tendem a seguir uma mesma configuração cromática, como o piso cinza, as paredes beges e brancas, as portas azuis ou verdes. A pesquisa nos revela que esse padrão não deve existir, pois cada ambiente tem suas funções e o mesmo deve estar adequado de diferentes formas sob o foco no ser humano.

A realização deste estudo nos permite inferir que efetuar uma análise cromática do projeto antes de sua execução poderá trazer benefícios no processo de execução e no resultado final do projeto. Um ambiente cromaticamente adequado além de exercer uma influência importante nas atividades dos usuários, deixarão os mesmos mais satisfeitos e produtivos. Outro fator importante é a geração de economias financeiras para a instituição, uma vez que um projeto bem elaborado não precisa ser refeito. Além de possibilitar melhores índices de classificação de ensino para universidade, através dos melhores rendimentos que o ambiente poderá proporcionar aos alunos.

\section{REFERÊNCIAS BIBLIOGRÁFICAS}

ASSOCIAÇÃO BRASILEIRA DE NORMAS TÉCNICAS. NBR7195:1995 - Cores para Segurança.

CARNEIRO, Rosângela Maria de Souza. A cor nas salas de aula do ensino médio [dissertação]: recomendações com base em estudos de escolas em Florianópolis - Florianópolis, SC, 2012. 
COSTI, M. A INFLUÊNCIA DA LUZ E DA COR EM CORREDORES E SALAS DE ESPERA HOSPITALARES. Porto Alegre: EDIPUCRS, 2002.

DEL RIO, Vicente. Cidade da Mente, Cidade Real: Percepção Ambiental e Revitalização na Área Portuária do RJ. In: DEL RIO, Vicente; OLIVEIRA, Lívia (Orgs). Percepção ambiental: A experiência brasileira, p. 3-22, 2ª ed. São Paulo: Studio Nobel, 1999.

FONSECA, Juliane Figueiredo. A Contribuição da ergonomia ambiental na composição dos ambientes construídos de locais de trabalho de escritório. Dissertação de Mestrado Departamento de Artes e Design, PUC do Rio de Janeiro. Rio de Janeiro, 2004.

GURGEL, Mirian. Organizando espaços: Guia de decoração e reforma de residências. $2^{\circ}$ edição. São Paulo: Editora Senac, 2012.

HELLER, Eva. A psicologia das cores: Como as cores afetam a emoção e a razão. $1^{\circ}$ edição. São Paulo: Gustavo Gali, 2013.

IIDA, Itiro. Ergonomia: projeto e produção. $2^{\mathrm{a}}$ edição rev. e ampl. São Paulo: Blucher, 2005.

LACY, Marie Louise. 0 poder das cores no equilíbrio dos ambientes. 5o ed. São Paulo: Pensamento, 2011. 144p.

MATEUS, Tiago Henrique de. et al. Avaliação Luminotécnica nas Salas de Aula da Unidade VII no campus da Universidade Federal de Mato Grosso do Sul. Anais da 57ํ Reunião Anual da SBPC. Fortaleza, CE - Julho, 2015.

OKAMOTO, Jun. Percepção Ambiental e Comportamento. São Paulo: Mackenzie,2002. PRADO, Heloisa, 2003. A Organização e administração de bibliotecas. $2^{a}$ Ed. São Paulo: T.A Queiroz. P. 129 e 130.

RANGEL, Márcia Moreira; MONT'ALVÃO, Cláudia. A observação do comportamento do usurário para o wayfinding no caminho construído. 15 ERGODESIGN - Congresso Internacional de Ergonomia e Usabilidade de Interfaces. Recife, PE, junho de 2015.

RAPUANO GUIDALLI, Cláudia Rocha. Diretrizes para o Projeto de Salas de Aula em Universidades Visando o Bem-Estar do Usuário. Dissertação de mestrado em Arquitetura. UFSCPOSARQ. Florianópolis, 2012.

RHEINGANTZ, P. A.; ALCANTARA, Denise de; RIO, Vicente del. A influência do projeto na qualidade do lugar: Percepção da Qualidade em Áreas Residenciais do Rio de Janeiro. Sociedade e Território - Revista de estudos urbanos e regionais - \# 39. Rio de Janeiro, dezembro 2005.

SILVA, V. L.A; BORMIO, M. F. A importância do uso da cor na interface ambiente $x$ usuário. 1ำ CONAERG - Congresso Internacional de Ergonomia Aplicada. Recife, Pernambuco, novembro de 2016.

SOBRAL, E. R. F.A.; PAIVA, M. M. B.; PORTO, N. R. S.; VILLAROUCO, V. M. Discussão acerca da percepção ambiental, suas ferramentas e cognição. 15 ERGODESIGN - Congresso Internacional de Ergonomia e Usabilidade de Interfaces. Recife, Pernambuco, junho de 2015.

STONE, N. J. Designing effective study environments. Journal of Environmental Psychology, v.21, p.179-190, 2001.

THOMPSON, S. Color in education. School planing and management; v. 42, n. 12, p. 30- 2; Dec. 2003. Published by Peter Education Group.

VASCONCELOS, C. S. F.; SOARES, M. M.; VILLAROUCO, V. M. Avaliação ergonômica do ambiente construído: Estudo de caso em uma biblioteca universitária. Ação Ergonômica - Revista Brasileira de Ergonomia. Ação Ergonômica. Volume 4, número 1, 2009. 